\title{
Marcas discursivas y narrativas del humor leve en Papelucho*
}

\author{
Edgardo Cifuentes ${ }^{* *}$
}

\section{Resumen}

En este trabajo se analiza la perspectivización humorística de los hechos en la novela infantil Papelucho de Marcela Paz, siguiendo una metodología basada principalmente en el ensayo de Ítalo Calvino, "Levedad". El análisis consiste en la detección de claves textuales que evidencien la predominancia de una conciencia y de formas de conocimiento inusuales en la observación de los hechos referidos; además, se consideran otras claves como la disolución de los referentes de las palabras y la aparición de imágenes figurativas de la levedad. Los resultados nos conducirán a realizar afirmaciones interpretativas a propósito de las particularidades del humor y de la visión de mundo, tanto del personaje como de la conciencia humorística que articula la narración.

Palabras clave: Papelucho, humor, levedad

\section{Narrative and discoursive marks of light humour in Papelucho}

\begin{abstract}
In this paper we analyze the humorous perspective of the events contained in the children's novel Papelucho, writen by Marcela Paz. The methodology is based mainly on the essay of Italo Calvino "Lightness". The analysis consists of detecting textual cues that evidence the predominancy of unusual consciousness and knowledge types while observing the referred facts; also, other cues such as word reference dissolution and the appearance of figurative images of lightness are considered. The results would lead us to make interpretative assumptions about the particularities of humor and world vision, from both the character and the humoristic consciousness that articulate the story.
\end{abstract}

Keywords: Papelucho, humor, lightness

Recibido: 24-03-2011 Aceptado: 9-05-2011

* Este artículo es un fragmento y adaptación del texto "Construcción humorística significativa en Papelucho" (seminario para optar al grado de Licenciado en Educación, mención Español, Universidad de Concepción), dirigido por la Dra. Cecilia Rubio. Aprovecho esta nota para agradecer a la Dra. Rubio su dedicada labor en la dirección y sus valiosos aportes al trabajo.

** Magíster en Lingüística Aplicada. Universidad de Concepción. ecifuentes@udec.cl 


\section{Introducción}

En el presente trabajo estudiamos el humor en tanto mecanismo significativo en la construcción de una obra literaria; específicamente, buscamos determinar cómo los distintos mecanismos del humor permiten reconstruir, desde una perspectiva analítica, el universo discursivo de la novela Papelucho de Marcela Paz, en lo que respecta al autor implícito, al narrador y al lector ideal. Para nuestros propósitos, definiremos el humor en un sentido general, como el "Modo de presentar, enjuiciar o comentar la realidad, resaltando el lado cómico, risueño o ridículo de las cosas" (DRAE, definición para humorismo).

Consideramos que este mecanismo de construcción de la realidad discursiva del personaje de las novelas de Marcela Paz constituye un problema de investigación relevante por dos motivos, principalmente: 1) porque se evidencia un rasgo importante en la obra, muchas veces destacado por la crítica, y aun así, sobre cuyos significados parece no haberse ahondado; 2) porque entrega claros indicios de la construcción del mundo ficticio representado y del sistema axiológico al que adhiere el autor implícito ${ }^{1}$.

\section{Algunos antecedentes}

Sobre Papelucho -o cualquiera de las novelas que protagoniza el personaje- no se ha escrito mucho más que breves comentarios. Peña, por ejemplo, destaca en la novela "La liviandad del relato, su jocosidad, ingenio, picardía y amenidad [que] lo han convertido en un clásico de la literatura infantil chilena" (1892: 70) y comenta una selección de fragmentos, constatando "el estilo asociativo de Marcela Paz y su jocosidad al describir al personaje y su particular manera de ver el mundo" (Peña, 1982: 71). Este juicio sobre la obra de Marcela Paz -en su brevedad-nos confirma una opinión común²: es capital para la construcción del per-

1 El autor implícito (también llamado autor implicado) es una instancia literaria teórica que se puede definir, en palabras de Booth, como la "versión creada, literaria, ideal de un hombre real" (Reis y Lopes, 1996: 28); esta figura, según J. Lintvelt, "representa el sentido profundo, la significación de conjunto de la obra literaria" y se puede considerar responsable de "la percepción intuitiva de un todo artístico completo" (Reis y Lopes, 1996: 28). El autor implícito es la entidad literaria más cercana al autor real. Él -y no el narrador- es la conciencia humorística, porque el personaje la mayoría de las veces no pretende ser cómico con sus comentarios.

2 Podemos recoger estas impresiones en artículos de prensa y otros similares disponibles en Internet. Algunos de ellos están digitalizados en la colección del sitio Memoria Chilena (memoriachilena.cl), como es el caso de una nota en el diario La Época del 16 de junio de 1995, titulada "Un genial aventurero: once títulos dan forma a la saga de este inolvidable personaje infantil".

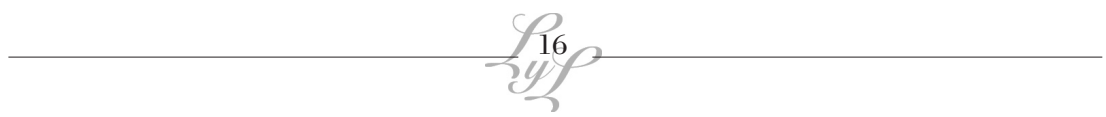


sonaje y la obra el desarrollo de una 'particular forma de ver el mundo', que dota a la narración de gran parte de su comicidad.

A partir de esta crítica recurrente, proponemos este estudio como una profundización sobre la importancia del humor para la construcción del universo discursivo de la novela Papelucho y la formación en el lector de la expectativa de levedad.

\section{El humor}

Distintas aproximaciones reflexivas al humor identifican en él al menos dos elementos constituyentes. En primer lugar, es necesario un 'hecho risible': el humor parece relacionarse con la realidad de manera polémica; hay algo en ella que causa molestia y se necesita dar a conocer. Aristóteles, en la Poética, identifica esa realidad molesta con los vicios que no significan un daño para nadie; Bergson (1943), con la rigidez y automatismo inconsciente que conducen el actuar de quien resulta cómico; para Freud (1956 [1952]), son aquellos hechos, situaciones, supuestos sociales, etc., que nos parecen reprochables; y para Jolles (1971), lo insuficiente, censurable o severo. En segundo lugar, es necesaria una 'liberación del peso psicológico' que la relación polémica con la realidad supone. Para Freud, por ejemplo, el humor es un placer proveniente de la liberación defensiva y consciente de los "afectos dolorosos" acumulados por el ser humano en su psiquis (1956 [1952]: 207); para Koestler, la creación humorística es de naturaleza evasiva, ya que funciona como una explosión frente a la presión, liberando toda la tensión acumulada en una situación (2002 [1964]: 198).

De este modo, podemos entender la naturaleza del humor como racional y emocional: racional, de momento que supone un 'punto de vista crítico' de la realidad; y emocional, porque es también una actitud frente a lo criticado, caracterizada por la experimentación de 'distensión'. Ambos componentes son necesarios pero no suficientes para causar el efecto cómico; en su intersección parece encontrarse el germen del humor: cuando una realidad criticable, severa, seria, se mira desde una lógica distinta, se logra la perspectiva humorística; en este cruce sucede el descubrimiento de la oculta semejanza entre lo serio y lo banal.

\subsection{Levedad: perspectiva de quien ríe}

Según Bergson, para que se logre el efecto cómico, es necesaria una particular perspectiva de observación de las desviaciones de la norma: la 
conciencia de la rigidez y automatismo que conducen a quien actúa de manera risible; cuando alguien se percata de este automatismo (mientras que quien actúa no lo descubre), se produce la perspectiva humorística (Bergson, 1943: 20-21). Koestler nos llama la atención sobre la necesidad de un "clima emocional" específico desde el cual se observe un hecho para que pueda surgir la creación humorística (2002 [1964]: 208-209); afirma que tanto el arte como la ciencia utilizan: 1) idéntico objeto de trabajo que el humor: la misma realidad puede ser vista de distinto modo por un poeta trágico, por un científico y por un humorista (Koestler, 2002 [1964]: 209), y 2) un patrón lógico semejante para la creación: "el descubrimiento de las similitudes ocultas" (Koestler, 2002 [1964]: 191); el clima emocional necesario para que se produzca el humor es la perspectiva absurda, en oposición a la abstracta y objetiva (científica) y a la trágica o lírica (Koestler, 2002 [1964]: 191-192). Para Jolles es fundamental en la construcción del humor la voluntad del humorista de romper el pacto de comunicación que salvaguarda la seriedad y subvertir las realidades ordinarias, ya sean éstas lingüísticas, éticas, lógicas, etc. (1971: 226). Estas reflexiones nos llevan a afirmar que un componente esencial de una estructura de lo cómico es la perspectiva especial del humorista.

La 'levedad', según Calvino, es una propiedad y valor de una mirada especial de la realidad, y se produce cuando esta se observa indirectamente o a través de "otra lógica, otros métodos de conocimiento y verificación" (2001 [1998]: 22), distintos de los que la pesadez de lo concreto y real parecieran sugerir. De esta manera, la propiedad y valor especial de la perspectiva leve se caracteriza por la superación de la pesadez del mundo, para ser reemplazada por un 'ritmo' que se adhiere a la imagen de la realidad y que no proviene de esta, sino de la propia interioridad y actitud de quien observa. El producto de una mirada indirecta y leve de la realidad es una imagen del mundo en la que este ha perdido el peso de los personajes, los hechos, las estructuras e incluso del propio lenguaje (Calvino, 2001 [1998]: 19).

La segunda característica de la levedad es la abstracción. Por oposición a la concreción de las imágenes con un asidero directo en la realidad, en las que el lenguaje adquiere el peso de la masa corpórea, las imágenes de levedad aparecen como abstracciones sin asidero en un lugar concreto, destinadas solo a buscar efectos (Calvino, 2001 [1998]: 31). De esta distinción se infiere que la visión leve es una construcción indirecta y alejada de la pesadez material de la realidad.

A partir de la reflexión de Calvino, y con el objeto de diseñar una metodología de análisis aplicable a nuestro objeto de estudio, siste-

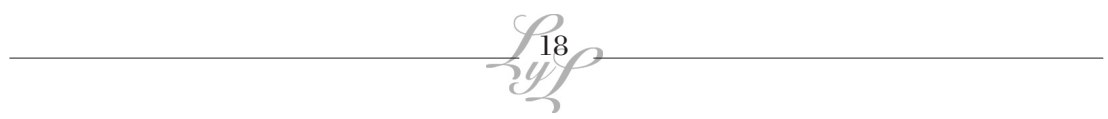


matizamos algunas de las formas en que se manifiesta la levedad en la superficie textual:

a. Evidencia de una conciencia alterna. Para Calvino la mirada leve transforma la pesadez del mundo en una imagen liviana (2001 [1998]: 19-20); así, constata que la poesía de Cavalcanti trata una temática nada leve -como el amor-, que el autor descompone en entidades leves e impalpables, como espíritus o imágenes etéreas de belleza (2001 [1998]: 27-28); asimismo, en la obra de Shakespeare el drama de la vida (tema grave) se contempla desde un punto de vista externo que produce una imagen melancólica e irónica de ella (Calvino, 2001 [1998]: 34). De esta manera, la perspectiva leve produce la descomposición de temas graves en los detalles imperceptibles que los conforman, impidiendo imágenes dramáticas de las circunstancias y permitiendo una actitud melancólica o irónica.

Calvino sugiere que quien mira desde la levedad descubre que "todo está hecho de partículas leves y sin peso alguno" (2001 [1998]: 25); cuando centramos nuestra atención en estas partículas, se pierde la visión de la totalidad grave y pesada. Así, cuando frente a una situación enorme, apocalíptica y oscura, se centra la atención en lo tenue de ella, se está procediendo desde la levedad. Esto es posible debido a que, si atendemos a los detalles, la organización previa y establecida del mundo se pierde y se configura una nueva, en la que los hechos no son solo los constructos sociales convencionales sino también una suma de detalles ínfimos y sin importancia aparente.

b. Formas de conocimiento alternas. Otro indicio de la mirada leve es la presencia de ópticas, perspectivas y métodos de conocimiento diferentes de los esperables (Calvino, 2001 [1998]: 23). Koestler ha definido con mayor detalle un rasgo del humor asimilable a esta óptica inesperada: el 'entrecruzamiento de matrices'. Este proceso consiste en la presentación de una matriz (marco de actitudes o acciones normales y esperables en una situación), que nos crea expectativas de la forma en que se actuará frente a un estímulo, para posteriormente romper estas expectativas; según el autor, la situación humorística se produce cuando esperamos una respuesta enmarcada en una matriz A, pero se responde inesperadamente con una actitud normal en una matriz B, con la cual A guarda alguna semejanza, que descubrimos al momento de reír (Koestler, 2002 [1964]: 199). De esta manera, cuando esperamos encontrarnos una mirada tradicional y convencional frente a una situación presentada en un texto, y en cambio nos encontramos con conclusiones nuevas que evidencian 
Marcas discursivas y narrativas del humor leve en Papelucho / Edgardo Cifuentes

perspectivas distintas de consideración de la situación, nos hallamos frente a señales de levedad.

c. Disolución de lo concreto en la palabra. Una tercera marca discursiva de la levedad es el "aligeramiento del lenguaje mediante el cual los significados son canalizados por un tejido verbal como sin peso" (Calvino, 2001 [1998]: 31), es decir, la pérdida del interés en los significados (y más aun, en el referente) por acción de un significante ligero, incapaz de transmitir el peso del mundo. Debemos notar que un significante con estas características recibe toda la atención que se quitó del referente; de alguna forma, es un signo referido a sí mismo.

d. Imágenes figurativas de la levedad. Por último, otra forma de manifestación es la imagen figurativa de la levedad que cristalice de manera certera esta forma de concebir el mundo y sus relaciones (Calvino, 2001 [1998]: 32). Así, escenificaciones de la levedad física, tales como la imagen del Quijote lanzado por los aires por las aspas del molino de viento, son evidencias de la perspectiva particular del texto.

Estas marcas de la levedad como actitud y perspectiva de la imagen que se nos presenta permiten acercarnos al objeto de estudio. El análisis consiste en la búsqueda de manifestaciones de la levedad, advertida a través de estas marcas.

\section{Manifestaciones del clima leve en el texto}

En este análisis de algunos de los elementos humorísticos de la novela, buscaremos comprobar la presencia transversal de la mirada leve en el texto, como constituyente del punto de vista del autor implícito y de la construcción del narrador protagonista.

\section{1. Evidencias de una conciencia alterna}

\subsubsection{Percepción cambiada de lo leve y lo grave de un asunto}

Estas evidencias corresponden a episodios de la historia cuyo tema comúnmente se considera grave ${ }^{3}$, pero es tratado en ella como si fuese leve.

3 En esta parte del análisis trabajaremos en base a episodios seleccionados de la novela. Entendemos el concepto de episodio como la "unidad narrativa no necesariamente demarcada exteriormente, de extensión variable, en la que se narra una acción autónoma con relación a la totalidad de la sintagmática narrativa, acción que se conexiona con el todo que se incrusta a través de cualquier factor de redundancia" (Reis y Lopes, 1996: 77).

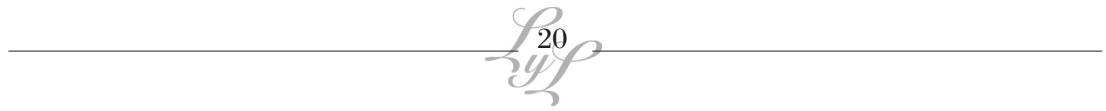


La fórmula inversa (tratar lo leve como grave) parece lograr el mismo efecto: en ambos casos el lector no espera que las consecuencias de los hechos relatados sean dramáticas.

La novela comienza con la suposición de Papelucho de que su experimento -introducido en un sándwich para observar qué sucedía si se lo comía un ratón- había sido ingerido por la Domi, la nana de su casa. Esto causa en él un constante estado de alerta y preocupación por la posible muerte de la Domi; este estado, sin embargo, se diluye con el tiempo, hasta que el personaje finalmente abandona el tema completamente y el lector no conoce cómo se solucionó el conflicto. Incluso hablando del tema, Papelucho olvida su preocupación original y discurre sobre otros asuntos relacionados de alguna manera con este (él iría a la cárcel, qué haría mientras está en la cárcel, etc.), los que finalmente concentran su atención; así sucede, por ejemplo, cuando el personaje afirma: "me dan ganas de que se muera pronto para poder arreglar mis cosas de una vez" $\left(11^{4}\right)$ o cuando decide hacerse santo -como promesa para evitar la muerte de la Domi-, recuerda que los santos regalan sus cosas y acaba comentando su deseo de que su hermano sea santo para que le regale su raqueta (12). El personaje que supuestamente peligra de muerte también reacciona ante esta posibilidad de manera leve: "[si supiera que me voy a morir] me daría una vuelta de carnero [...] porque la muerte es la felicidad del pobre. [Además] Me daría una fiesta y gastaría mil pesos en comer..." (9).

Una segunda forma de verificación del proceso de disolución de la tensión es la detección de episodios en los que una situación grave culmina rompiendo las expectativas serias que se pudo formar el lector.

Ejemplos de este caso podemos encontrar cuando Papelucho está jugando con su escopeta y esta se le dispara (32), sin ninguna de las consecuencias serias esperables (apenas algún destrozo menor). Similar rompimiento de expectativas graves causa el episodio en que, con su hermano Javier, Papelucho enciende una fogata que se sale de control, hecho del que, sin embargo, no resulta ninguna consecuencia grave (55). Un último ejemplo aparece cerca del final de la novela, cuando Papelucho y un compañero del internado alojan en la bodega de este a un criminal, sin saber que era un asesino (119); aquí también las expectativas graves se diluyen en la desaparición y posterior detención del delincuente.

4 Se citará la novela Papelucho señalando sólo el número de página. 
Marcas discursivas y narrativas del humor leve en Papelucho / Edgardo Cifuentes

Otra forma de verificar la visión leve de un suceso grave es detectar marcas de la "ingenuidad" del personaje protagonista con respecto a lo leve/grave: su proceder confiado en que de sus acciones no provendrán consecuencias graves o reacciones reprobatorias, aunque para el lector y para el sentido común, estas resultan predecibles.

Podemos observar esta forma de percepción cambiada de lo leve/ grave cuando el protagonista nos cuenta cómo decidió partir a unas vacaciones a Viña sin más ropa que la puesta, por considerarla innecesaria (21-22). Durante el mismo viaje, comete otra ingenuidad: trata de remediar una mancha de aceite de motor en su pantalón untando de aceite todo el pantalón, para emparejarlo (22); mientras esperaba que se secara, lo escondió y usó unos prestados por su hermano Javier; pero como le quedaran largos, creyó que no pasaría nada grave si les "cortaba una tajadita" (23). En otra ocasión, Papelucho cree una excusa muy inverosímil que le da la Domi -la nana de su casa- para salir de noche: le dice que necesita hacer una diligencia; cuando regresa -en la tarde del día siguiente-, el niño también le cree su excusa para justificar su atraso: se había caído de la micro y había quedado inconsciente hasta entonces (46). En otro momento, fantaseando a partir de unos peces y jaibas que le han regalado, Papelucho planifica: "cuando tengan hijos, voy a poder vender mucho pescado y tal vez me haga rico y después viviré sin trabajar" (39). Un último ejemplo lo constituye la invitación a comer a su casa -sin avisarle a nadie- que Papelucho extiende a los ocho hermanos de Jacinto Soto, un amigo que recién viene conociendo (103). En este caso y los anteriores, las consecuencias y reacciones graves no son predichas por el personaje, aunque sí por el lector.

En algunos casos, como en el de las excusas de la Domi y la planificación del negocio de los pescados, la ingenuidad se da en un sentido distinto, pues no resultan consecuencias graves no previstas por el personaje. En este caso lo 'grave' es sinónimo de lo 'real', en el mismo sentido en que encontramos el concepto de gravedad en el ensayo de Calvino; es decir, lo grave que se esconde a la vista del protagonista no son las consecuencias de sus actos, sino la realidad tras la mentira de la Domi o la ficción del negocio del pescado, que el lector implícito (por lo menos el adulto) es capaz de vislumbrar, mientras que el personaje no.

Una variación de esta manera de construir la levedad en el texto es la perspectivización inversa: cuando un hecho que usualmente consideraríamos trivial es visto por el personaje como portador de gravedad. 
Tal procedimiento lo encontramos verificado en ejemplos como la idea del narrador de que es posible que se muera al sufrir un simple resfrío (17); la transformación de los preparativos para un viaje en "retos", "destrozos" y "peloteras" (19); las conclusiones acerca de la relación con sus padres que obtiene Papelucho a partir de algunos conflictos con ellos (por ejemplo, "mi padre es cruel y me aborrece" (27)); el hecho de planificar como un negocio rentable la crianza de un par de jaibas y estrellas de mar (39); entre otros. En estos casos, la exageración de la gravedad de un asunto otorga levedad al clima del texto; esto se produce porque, aunque el narrador nos está hablando en tono grave, sabemos que en el hecho narrado no hay tal gravedad.

Podemos concluir, a partir de estos ejemplos, que la configuración literaria de la personalidad de Papelucho nos postula un personaje distinto a los adultos, sin preocupaciones absolutamente graves y que no espera consecuencias graves de sus acciones; mientras, se nos presenta un adulto con el deber de preocuparse por la seguridad del niño y, por lo tanto, de anticipar las peores circunstancias, de adelantar realidades graves, de pensar de manera realista. Así, la construcción de la conciencia infantil la hallamos caracterizada por la voluntad y certeza de que de las acciones resultarán consecuencias positivas o leves, aunque esta certeza se aleje del análisis realista de los hechos. Vemos, además, que para reaccionar con la risa ante el quiebre de las expectativas normales de las distintas situaciones, el lector implícito necesariamente debe formárselas espontáneamente, a partir de los hechos; esto nos lleva a suponer que algunos de los elementos humorísticos del texto estarían especialmente dirigidos a lectores que posean un conjunto suficiente de convencionalismos que en la misma novela se postulan como propios de los adultos.

\subsubsection{Preocupación por los detalles leves de lo grave}

Ejemplos de este caso los hallamos en la descripción del invento con el que Papelucho quería experimentar qué le sucedía a un ratón si se lo comía: "tenía dos cajas de fósforos, Rinso, miel de abeja, un poco de aceite, crema para la cara y pólvora" (9), minucias cotidianas y aparentemente inofensivas, que unidas forman una mezcla peligrosa. Una actitud leve frente a la muerte se demuestra cuando se preocupa por un aspecto trivial del fallecimiento de su vecina: la presencia en la calle de muchos vehículos y de "dos Mercedes Benz de ocho cilindros" (15). Mientras lo aqueja un resfrío -y pensando en la posibilidad de que lo mate- se da tiempo para calcular que "sólo después del almuerzo" ha tosido "ciento 
ocho veces" (16); también comenta las ventajas (esos detalles usualmente desapercibidos) de este mismo estado de enfermedad: no lo retan cuando hace algún destrozo, lo llaman "el niño", le hacen sopa especial y le piden que se la tome "como suplicándole", le prometen todo "lo que necesita", se lava con agua tibia y si no quiere no se lava (17).

Otro ejemplo lo verificamos cuando se escapa de su casa y se queda dormido en un potrero; al despertar ve gente jugando fútbol y ese suceso -que es una circunstancia del principal (el despertarse en un potrero)pasa a primer plano: él se ocupa de hablar del partido de fútbol en lugar de su despertar; nos informa que "ganaron los azules" y todavía más "por tres goles" (28). Cuando va con su familia al campo de la tía Rosarito, cuenta lo que hacen en el día, dando claro ejemplo de una organización aleatoria de detalles:

Con Javier salimos a caballo todo el día. Ahora, él es bien amigo mío y los dos somos amigos del Chirigüe. Hay un caballo ciego que me da mucha pena y le doy de comer con la mano.

Hicimos un picnic con Javier y nos comimos seis huevos cada uno y una sandía cada uno. Después nos dimos un baño de barro y otro de agua del estero. Salimos a caballo ocho veces en el día y anduvimos en carreta y en tractor. También aprendimos a lacear y a lechar vacas. Lo importante es la cola porque colea los ojos. También regamos la chacra y no tomamos té porque la leche de vaca es rica en el balde. (49-51)

Otro ejemplo de descripción aleatoria y detallista es el que hallamos cuando el personaje describe su estadía por rubéola en la enfermería del internado:

Me dan limonada y me prestan los álbumes de fotos que son todos iguales. El Padre rector me vino a ver y me contó un milagro. El enfermero es tan turnio que se le cruzan los ojos y es todo hecho como de goma de borrar [...]

En el techo de la enfermería hay una arañita y una grieta que parece un río de mapa. (80)

Una elección de lo ínfimo y poco significativo, de entre los hechos susceptibles de ser considerados como sacrificios, es lo que observamos cuando Papelucho "hace promesa" de no hablar o de no mirar para atrás para que se le quite el dolor de estómago (61). El mismo tipo de selección de sus preocupaciones se puede ver cuando piensa en la posibilidad de quedarse cojo por dar saltos mortales, y lo considera poco importante

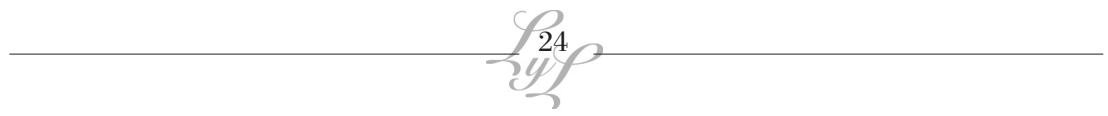


"porque los piratas siempre tienen una pierna de palo" (100). Frente a la muerte del padre de un compañero del internado, su preocupación se centra en cómo se vería la hermana de este llorando y vestida de negro (91); de similar manera, cuando muere un vecino de su edificio, y entra a su casa durante su velatorio, lo que le preocupa es la presencia allí de "un barómetro de esos estupendos" (102).

De esta forma, el narrador, al centrar su atención en los detalles de los hechos graves, hace perder la visión de totalidad y construye para sí mismo, y para el lector, una nueva perspectiva de estas situaciones.

\subsection{Formas de conocimiento alternas}

\subsubsection{Evidencia de opinión sesgada}

Consiste en evidencias explícitas de diferencia de opinión o perspectiva entre el narrador y los demás participantes del mundo narrado (principalmente, los adultos). Además incluimos, como una manifestación de la diferencia de opinión, las evidencias de perspectivización focalizada en la propia individualidad del narrador.

En primer lugar, ejemplos de la explicitación de la diferencia de perspectiva a través de comentarios del personaje podemos encontrar en fragmentos como: "mi papá dice que él, a la edad de nosotros, nunca se aburría, pero yo creo que les voy a decir lo mismo a mis hijos" (25), "Sería mejor que cuando uno está enfermo lo dejaran morirse y lo embalsamaran después. Así sería como quieren que uno sea" (37), "esto lo llaman educar y yo lo llamo tenerle pica a uno" (47), "Parece que se mató un caballero por amor en el piso de arriba. Yo no me mataría ni siquiera por un auto de dieciocho cilindros" (57), "Si el Padre Carlos cree que esto es 'lo que no me importa' está sumamente equivocado, porque me importa tanto que pienso todo el tiempo en él" (72). En todos estos casos, la diferencia de perspectiva entre Papelucho y los adultos se manifiesta por discrepancias entre las órdenes de las autoridades y la voluntad del niño: la autoridad representa la perspectiva grave (porque busca el orden, la seriedad), y la voluntad infantil de despreocupación de las normas y de espontaneidad en los actos representa el actuar guiado por la levedad.

En segundo lugar, hemos distinguido la perspectivización focalizada en la propia individualidad del narrador; esta consiste en la exposición de percepciones personales como si fueran realidades objetivas, naturales y evidentes. Vemos esto claramente ejemplificado en comentarios como: 
Marcas discursivas y narrativas del humor leve en Papelucho / Edgardo Cifuentes

"esta casa es fea y ajena y me revientan las casas ajenas" (48); "Parece que se mató un caballero por amor en el piso de arriba [...] Ayer fuimos al cine y era todo de amor. La radio también habla de amor y de besos y los cantos igual. Antes no era así, pero ahora todo se vuelve puro amor" (57); en este ejemplo podemos notar que la repentina atención sobre un tema lleva al protagonista a percibirlo más a menudo en el entorno; sin embargo, para él, no se trata de un asunto de percepción, sino de lo que realmente sucede.

\subsubsection{Prioridades diferentes}

Este tipo de evidencia la hallamos en la preocupación del personaje por los aspectos generalmente considerados no importantes de las cosas. Este es el caso de cuando Papelucho se quiere hacer santo y regala sus cosas, pero sólo lo que considera sin utilidad; al contrario, conserva algunos objetos que "necesita": pelota, escopeta, revólver y otras cosas (12). Otro ejemplo lo encontramos en las indicaciones que deja Papelucho a su familia en caso de su muerte: "que no me registren mis cajones y que le den alpiste a mi canario" y "que le compren chocolate a los niños pobres en mi honor" (17); efectivamente, a ojos de un adulto, "los niños pobres" sufren privaciones más prioritarias que el chocolate.

Ejemplos que dejan ver las prioridades respecto a los objetos vemos, por ejemplo, cuando Papelucho prepara su maleta para viajar a Viña y, por repletarla con objetos que juzga más importantes, no tiene espacio para llevar su ropa (20); otro ejemplo se verifica cuando decide reunir dinero vendiendo todas las cosas de la casa "que no sirven o que no se usan": "corbatas inútiles, los guantes, los pinches y prendedores y pulseras que no se usan y unas dos carteras" (37). En estos casos, el lector puede incluso prever las consecuencias, pues sabe que los objetos que al niño le parecen inútiles, para los padres son importantes y que cuando estos se enteren de lo que hizo, lo reprenderán.

\subsection{Disolución de lo concreto en la palabra}

\subsubsection{Términos utilizados en contextos poco usuales}

El primer mecanismo de disolución de lo grave a través del lenguaje consiste en la utilización de palabras en contexto -lingüístico y situacional- poco usual. Ejemplo de esto es el comentario del personaje a propósito de su criadero de jaibas y de la muerte de una de ellas: "No se movía y tenía verdadero olor de muerte" (40); en este caso, el adjetivo

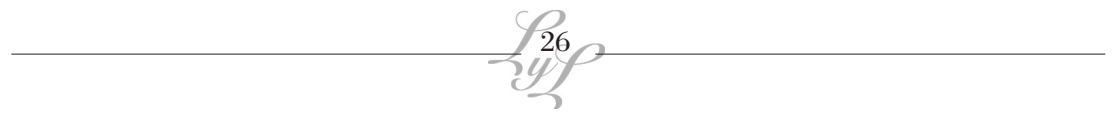


"verdadero" es el que nos parece fuera de lugar, ya que no lo reconocemos como una cualidad fácilmente aplicable a la descripción de un olor (basta oponer "verdadero olor de muerte" con "falso olor de muerte" para darnos cuenta de que la adjetivación es bastante arbitraria). En otro episodio, el personaje se felicita por su éxito en los saltos: "sé que hago las cosas bastante perfectas" (89); en este caso, el adverbio "bastante" determina a "perfectas", adjetivo que no reconocemos susceptible de gradación; así, el personaje relativiza el significado de "perfecto", y lo hace de una manera imprecisa y despreocupada.

Otro ejemplo claro, evidente en un conjunto de términos, es el episodio en que Papelucho relata la muerte de un ratón (que fue su mascota durante un día) como si fuera la de un humano: "preferí enterrarlo y hacerle una sepultura en el jardín. Me da arrepentimiento que me lo hayan regalado para venir a morir asesinado cuando era tan feliz con los Soto" (109; nosotros destacamos). En otra ocasión, describiendo a la hermana de un amigo, Papelucho utiliza términos provenientes de distintos ámbitos para referirse a sus cualidades: "La hermana de Gómez es colosal. Tiene unos ojos negros bien picantes y cuando se ríe se le abolla la cara y da como cosquillas" (91; nosotros destacamos).

\subsubsection{Referente vacío o distante}

El segundo mecanismo consiste en la utilización del lenguaje para referir hechos que no existen en la realidad en el mundo narrado. Una primera forma de este mecanismo son los engaños que utiliza Papelucho para salir de aprietos sin decir la verdad, y a la vez sin mentir formalmente. Un ejemplo de esta situación se verifica cuando el personaje quiere evadir la atención sobre un desastre en el que ha tenido parte, y para eso relata a su padre un accidente que presenció, sin mencionar que había sido días antes; el padre cree que el evento fue reciente e incluso nota palidez en el hijo, la que atribuye a la impresión; Papelucho se justifica ante su lector: "no es que uno sea hipócrita si lo creen pálido cuando uno está pálido" (20). Otro ejemplo lo hallamos cuando, tras haber dañado la pared de la casa con su rifle, Papelucho le pregunta a su padre: "isentiste el temblor?" (33); así consigue que su padre atribuya el daño en la pared a un temblor, sin mentir expresamente. En ambos casos, se aprovechan en beneficio propio las ambigüedades del lenguaje.

La segunda forma de este mecanismo consiste en la exageración de la realidad; esta causa un alejamiento del lenguaje de su valor positivo de verdad y de su relación con el referente. Para este caso, encontramos el 
ejemplo de Papelucho, que, castigado y molesto con sus padres por ese castigo, relata con despecho: "Con Javier subimos al tejado y lo pasamos regio. Encontramos una pelota seca y un calcetín guacho" (24; nosotros destacamos). Exageraciones en torno a su relación con sus padres y a su fuga de la casa observamos en distintas expresiones: "Huir de las injusticias de la vida" (26), "Mi padre es cruel y me aborrece" (27), "[a mi madre] le hace bien ver que su hijo la abandona" (28; nosotros destacamos).

La tercera forma de este mecanismo consiste en la utilización del lenguaje figurado; en este, una imagen figurativa interpuesta produce una mayor distancia entre las palabras y el referente. Un primer ejemplo lo encontramos en la afirmación de Papelucho: "yo no aprendí a nadar porque el mar ni lo deja a uno" (47); en ella, atribuye al mar capacidades humanas, una especie de voluntad. Otro ejemplo es la comparación poco usual: "mamá se aburre como caracol con la tía Rosarito, teje que teje" (55). Por último, un ejemplo que nos muestra claramente la levedad del lenguaje figurado surge cuando el rector, a propósito de una revista "ofensiva" que Papelucho y Gómez editaban en el colegio, les pregunta: "i[...] publican ofensas gratuitas a sus profesores?"; ellos no entienden el sentido figurado de "gratuitas" y responden alejándose del significado: "Gratuitas no, Padre. Pagadas." (113), pues retribuían con veinte pesos las colaboraciones para la publicación.

Al despojar o alejar al significante de su referente, mediante la descontextualización, el falseamiento y la creación, el lenguaje pierde la gravedad dada por su relación con la realidad y se vuelve vacío, se centra en sí mismo. Esto implica que el lector no se ríe de la realidad, sino de su representación abstracta; así, se estimula una risa crítica y reflexiva, que no pretende destruir los elementos de la realidad a los que hace distante referencia. Tal forma de humor es llamada usualmente 'ironía' ('broma', para Jolles), y se caracteriza por ser, en último término, compasiva, condescendiente y cercana con la realidad que critica ${ }^{5}$. De esta

5 Para Bryce Echeñique:

Las palabras irónicas -a diferencia de las del humor quevedesco-se lanzan más como plumillas de badmington que como saetas o dardos envenenados, y luego penetran en el corazón de los hombres pero sin inferirles un daño muy profundo. Suelen suscitar leves sonrisas porque son burlonas y no sólo afectan a quien van dirigidas, afectan también a quien las profiere. La ironía, esta burla fina y disimulada, puede elevarse a consideraciones negativas sobre el mundo en general y sobre la sociedad en particular, porque es la secreta armadura del yo. A la vez, la ironía es un juego alegre, un placer refinado de la inteligencia, pues negar la moralidad convencional y burlarse de ella proporciona mayor intensidad a la fruición estética.

La ironía es sentimental y, a la vez, intelectual, cuando la agudeza de la mente se asocia a la intensidad emotiva del sentir. (Bryce Echeñique, 2000: 383). 
manera, el texto no pretende enfrentar al lector infantil postulado con la realidad en una relación destructiva, sino mostrarle de manera más llevadera lo severo y grave del mundo real.

\subsection{Imágenes figurativas de la levedad}

Esta manifestación de la levedad consiste en el entrecruzamiento del lenguaje escrito con el lenguaje visual (como el del teatro o del cine). En estos episodios, lo más relevante no es la narración, sino la visualización mental que podamos formarnos de la escena; esta imagen además representa de manera simbólica otro concepto, abstracto y no visible, como es la perspectiva leve ante la realidad.

Una visión de este tipo imagina Papelucho a propósito de una mosca que está amaestrando: "Creo que hasta puede llevar un átomo y servir de bomba" (18). Una comparación leve entre una imagen potencialmente temible y una simple y cotidiana se puede ver en un sueño del protagonista: "[soñé que los acontecimientos] eran hombres vestidos de uniforme y llenos de clavos, algo como las sillas del comedor" (52). Una apacible y leve imagen cotidiana estimula la curiosidad de Papelucho en el siguiente fragmento: "[tía Rosarito] se lo pasa sentada en una silla mascando algo que no se traga y pensando en algo que no dice" (49).

Otra imagen de levedad se encuentra en el relato de cómo se escapan los ratoncitos de los Soto en el departamento de la familia de Papelucho y el departamento del vecino; las consecuencias son gritos de los vecinos y la Domi y muchos destrozos: "el agua y la sangre corrían y el ratón también y los Soto también", "todo parecía una verdadera piscina y dos Soto se cayeron y se empaparon" (105). En otro episodio, Papelucho y su compañero planean crear un circo y él reparte las funciones: "Gómez va a ser el que doma las fieras y yo el de los caballos, el de las botellas, el de los platos en el aire y el de los trapecios" (116); en este caso, la imagen de la levedad está dada precisamente por los actos que desafían la atracción gravitatoria.

Ciertas imágenes de levedad no son hechos narrados, sino comentarios del personaje, especulaciones, comparaciones, etc. Ejemplos de estas imágenes figuradas son: el comentario de Papelucho acerca de su habilidad de copista de "castigos" (tareas de repetir oraciones muchas veces): "yo escribo tan ligero como una máquina" (78); su explicación de su felicidad a través de una imagen: "Tengo ganas de cantar al aire libre y creo que si hoy me pudiera bañar en el mar, sabría nadar" (89); su percepción distorsionada de las distancias y de las posibilidades 
Marcas discursivas y narrativas del humor leve en Papelucho / Edgardo Cifuentes

físicas: "Yo no creo en la cuestión de que las lluvias son nubes derretidas. Yo creo que son estornudos de otros planetas" (91), que plantea imágenes leves de "estornudos" viajando por el espacio. Otra forma de transformar un concepto en una imagen visual son las hipótesis que se plantea Papelucho sobre las almas: “¿Cómo serán las almas? A mí se me ocurre una cosita blanca con la forma de Australia [...] el alma del Padre Carlos debe ser hinchada y la del Padre Lynn muy rosada y blanda y la de Reyes con hoyitos" (92).

Por oposición a estas imágenes de levedad, un hallazgo interesante resulta una imagen de pesadez como: "el desayuno lo tuvo que hacer mi mamá y rezongó tanto que era como si me martillara la cabeza" (46); aquí se presenta la reacción del personaje ante la percepción grave de los hechos por parte de los adultos.

De esta manera, las imágenes de levedad, entendidas como representaciones visuales que cristalizan el concepto abstracto de levedad, aparecen en el texto como afirmación del clima liviano, poco severo e ingenuo que constituye la forma en que Papelucho se relaciona con el mundo.

\section{Conclusiones}

Hemos establecido la necesidad de dos elementos constituyentes del humor: una realidad 'criticable' (ya sea por sus defectos morales, ya por su severidad) y una perspectiva especial de la conciencia humorística que observa esa realidad. De esta conjunción racional (por la crítica a la realidad que realiza), surgiría una creación humorística libre del peso psicológico que la relación con la realidad criticable supone; es decir, se genera una distensión, un resultado emocional. Seguimos a Jolles al afirmar que de la relación con la realidad insuficiente o severa, puede surgir una creación distendida; esta es la lógica humorística.

En este análisis descubrimos algunos rasgos de la perspectiva humorística actuando a lo largo de todo el texto; esta perspectiva la hemos identificado con el concepto de 'levedad', que propone Calvino.

En este trabajo hemos establecido una distinción entre la perspectiva usual, identificada con la visión 'adulta' de la realidad, y una perspectiva propia del personaje, que guarda diferencias muchas veces irreconciliables con la anterior. El texto constantemente enfrenta al lector con situaciones que generan expectativas graves, pero debido al clima de la novela, el lector sabe de antemano que tales asuntos tendrán un desenlace leve. La conciencia humorística de la perspectiva leve corresponde al autor

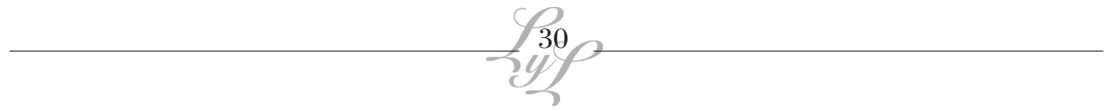


implícito y a la vez es compartida por el narrador; esto, en el entendido de que la vida psicológica del personaje se presenta como un trasunto más o menos cercano de la de un niño real ${ }^{6}$, supone la existencia de un lector implícito adulto que complete el sentido humorístico del texto, aportando el marco de expectativas que el personaje subvierte.

El análisis nos permite comprobar que el humor de la novela es de tipo 'inofensivo', pues no ataca directamente a la realidad, sino a una abstracción lejana de ella; de esta manera, no resulta destructivo para la misma. Este tipo de humor está destinado a producir una risa reflexiva y compasiva, condescendiente y afectuosa; en el caso de Papelucho, esta es la forma que el texto propone de mirar distanciadamente el mundo de los adultos y de las convenciones sociales. Si la novela postula un lector infantil además de un lector adulto, lo anterior deja planteadas interrogantes sugerentes: ¿cuál es la función y el efecto de la perspectivización leve en el lector infantil?, ¿será la mirada leve y condescendiente de la ironía una propuesta del texto para enfrentar al mundo grave de forma menos drástica?

\section{Referencias bibliográficas}

Bergson, H. (1943). La risa. Ensayo sobre la significación de lo cómico. Buenos Aires: Tor.

Bryce Echeñique, A. (2000). "Del humor quevedesco a la ironía cervantina", en Estudios Públicos, Volumen 77, p. 373-388.

Calvino, I. (2001 [1998]). Seis propuestas para el próximo milenio. Madrid: Siruela.

Freud, S. (1956 [1952]). El chiste y su relación con lo inconsciente. Buenos Aires: Santiago Rueda.

Jolles, A. (1971). Las formas simples. Santiago, Chile: Universitaria.

Koestler, A. (2002 [1964]). "El acto de la creación (Libro primero: el bufón)", en C.I.C. Cuadernos de Información y Comunicación, Volumen 7, p. 189-220.

6 No se debe suponer una relación semejante de forma tan apresurada; la tradición literaria contemporánea ha destacado especialmente el carácter autónomo de la literatura con respecto a la realidad. Sin embargo, la mayor parte de las teorías que hemos revisado respecto al humor asumen en este una necesaria relación con la realidad como parte de sus mecanismos que lo hacen efectivo; esta relación se da en forma de marcos de conocimiento de lo esperable en el lector implícito respecto a realidades representadas en la ficción; es decir, necesariamente la ficción ha de tener una intención representativa de la realidad, en alguna medida. Por esto mismo Bergson, Freud y Koestler vacilaban en incluir o definitivamente excluían el humor de la categoría de creación artística. 
Marcas discursivas y narrativas del humor leve en Papelucho / Edgardo Cifuentes

Paz, Marcela (1997 [1947]). Papelucho. Santiago, Chile: Universitaria.

Peña, M. (1982). Historia de la literatura infantil chilena. Santiago, Chile: Andrés Bello.

Real Academia Española (2001). DRAE. Diccionario de la Lengua Española. $22^{a}$ edición. Madrid: Espasa-Calpe.

Reis, C. y A. C. Lopes (1996). Diccionario de narratología. Salamanca: Colegio de España. 